fingers could be passed down into the tumour between the thighs.

Now, Sir, I felt this to be a very important case, and not having met with inversion before, I consulted many members of the profession with the like result; consequently I looked up all the books I could on the subject, and fail to find that inversion takes place during labour, excepting directly after the expulsion of the child. This fact, together with the ether evidence-viz., the length of time from the birth of the child to the birth of the placenta, its being adherent, and the statement that it was about an hour before the recovery of the placenta, also the general surroundings of the case-convinced me that inversion had taken place from the endeavour to bring away the placenta, which should have been done by introducing the hand into the uterus. This evidence I gave to the jury, and was supported by Dr. Eager. The jury returned a verdict of "Death from natural causes," and exonerated the midwife from blame.

Comment by me would be useless, if not dangerous, and I must leave that to my professional brethren, who I hope will state any cases of the kind they have met with, as they would be most instructive.

I trust, Sir, you will forgive the length of this letter. My excuse must be the importance of the subject.

I am, Sir, your obedient servant, ROBERT A. SkINNER, M.R.C.S.E.

Woking Station, April 21, 1879.

\section{COMPLETE TRANSPOSITION OF THE THORACIC AND ABDOMINAL VISCERA.}

To the Editor of THE LANCET.

SIR,-As I believe recorded cases of complete transposition of the thoracic and abdominal viscera are sufficiently rare to be worthy of notice, I send you the following notes of an autopsy made by me on the 5 th inst.

The man died from disease of the aortic valves, and on the only occasion on which I examined him before his death I diagnosed valve disease of the heart and transposition of the viscera. As the morbid appearances presented nothing of special interest I will trespass on your space with merely a description of the position of the viscera.

The heart was situated with its base behind the sternum, directed upwards, and to the left; its apex pointed downwards and to the right, and corresponded with a point about two inches and a half directly below the right nipple (the organ was enlarged, hence the apex was so far to the right).

The aorta wound over the root of the right lung, and descended along the right side of the bodies of the dorsal vertebrox. The arrangement of the branches of the arch was transposed, the subclavian and common carotid arising separately and supplying the right side, the innominate supplying the left. The branches arose from the arch from right to left in the order in which they are named.

Lungs: The left had three lobes, and was broader and shorter than the right. The right had only two lobes, and the lower part of its anterior border sloped downwards and to the right, leaving the pericardium uncovered; in fact, the normal lungs were transposed.

In the abdomen the large lobe (normally right lobe) of the liver was the left part of the gland, and occupied the left iypochondrium, and the right end (left lobe) extended into the right hypochondrium.

The stomach was situated in the right hypochondrium, with its greater end to the right. The descending portion of the duodenum was in front of the left kidney, the concave sile of the gut being in close relation with the head of the pancreas, which was therefore the left extremity of that organ. The spleen was situated in the right hypochondrium, its concave surface looking inwards and to the $l e f t$. The crecum occupied the left iliac fossa, and the sigmoid Hexure of the colon the right iliac fossa; consequently the ascending colon was on the right side, the descending colon on the left, and the course of the contents of the bowels throngh the transverse colon from left to right, the reverse of the normal direction.

$$
\begin{aligned}
& \text { I remain, Sir, yours faithfully, } \\
& \text { J. NORMAN DAvis, M.D., }
\end{aligned}
$$

Newbridge, Ireland, May 7 th, 1879.

\section{THE ARMY MEDICAL SERVICE.}

To the Editor of THE LANCET.

SIR,-The following anecdote in Gleig's " Life of Wellington" may interest some of your readers, especially "P. M. J.", as it shows that in 1812, at any rate, the Army Medical Department was not accustomed to public notice.

After the capture of Badajoz, Dr. M'Grigor, making his report to Lord Wellington, asked if his lordship was satisfied with the conduct of the surgeons. "Perfeetly," was the answer; "I saw with my own eyes that their exertions were superhuman." Dr. M'Grigor then proposed that they should be mentioned in the despatches by way of encouragement. Lord Wellington asked, abruptly, if that were usual ; but promised to "add something about the doctors"; and this, the author adds, is the first instance of their being mentioned, "and the good custom then established has never since fallen into abeyance."

May 17 th, 1879

Yours faithfully,

J. W.

\section{THE STATISTICS OF THE BIRMINGHAM LYING-IN CHARITY.}

To the Editor of THE LANCET.

SIR,-I trust that you will allow me to point ont that the use you make of these statistics is open to a very important qualification. The Birmingham Lying-in Charity refuses all unmarried women, and even then it has a very disproportionately small number of primiparæ. As it thus removes the most important factors of puerperal mortality, its statistics can serve no legitimate purpose, but to display the multiparous mortality in the decent artisan class.

Birmingham, May 27, 1879.

I am \&c.,

LAWSON TAIT.

\section{Obituatu.}

CHARLES BROOKE, M.A., F.R.C.S., F.R.S.

$\mathrm{By}$ the death of $\mathrm{Mr}$. Charles Brooke the profession has lost one of its most honoured members in the metropolis. He was a student of the now almost forgotten Windmill-street School of Medicine, and also of St. Bartholomew's. He long held a surgeonship in the Westminster Hospital, but had retired from the staff of the hospital and from practice several years before his death. He lectured for one or two sessions on Surgery at Dermott's School, having for colleagues the late Dr. Tyler Smith and Dr. Barnes. In 1844 the Royal College of Surgeons conferred upon him an honorary fellow. ship. He was, moreover, a graduate in Arts of Cambridge and wrangler, and a Fellow of the Royal Society. Mr. Brooke was best known to the profession and to the scientific world at large by his labours in physical science. To the medical men of the present generation he is chiefly known by his work, "The Elements of Natural Philosophy, or an Introduction to the Study of the Physical Sciences." This work forms one of the very best of Messrs. Churchill's series of Manuals, and although defaced by many badly-drawn illustrations, it is still unsurpassed as an elementary book. Originally written by Dr. Golding Bird, and particularly designed for the use of medical students, after having passed through three editions, "The Elements," on that physician's death, was entrusted to Mr. Brooke for editorship. 'The great progress which physical science had meanwhile undergone rendered it necessary to rewrite the work. The book lost nothing of its popularity in the process, while it was brought up to a higher level of thought without detriment to its original intention as a student's manual. Several editions of Mr. Brooke's "Elements" have appeared, and the book remains the best introductory work to the study of the physical sciences for the English student of medicine, if not for English students generally. At the present time, when there is a redundancy of textbooks on natural philosophy, and when the draughtsman's and engraver's arts have been employed to the uttermost in enriching them with beautifully-drawn illustrations, the 